\title{
IDENTIDADE E FORMAÇÃO DOCENTE: METAMORFOSES DE UMA GUERREIRA
}

\author{
Giovana Maria Belém Falcão (UECE)* \\ https://orcid.org/0000-0003-0995-1614 \\ Isabel Maria Sabino de Farias (UECE)** \\ https://orcid.org/0000-0003-1799-0963
}

\section{RESUMO}

Pensar sobre a constituição da identidade docente exige entender este processo como histórico, social e cultural, ao mesmo tempo, que é singular, trilhado por escolhas, ações, intenções, sentimentos e vivências. Este escrito tem por objetivo compreender o processo de constituição identitária de uma professora da Educação Básica na relação com a formação continuada. A pesquisa, de natureza qualitativa, buscou conhecer os movimentos identitários da professora, com apoio nas narrativas de história de vida. ${ }^{1}$ Mediada pela objetividade do mundo material e pelas relações que estabeleceu, a professora se subjetivou e se constituiu docente, vivenciando neste percurso, principalmente, a personagem "guerreira". 0 estudo aponta para a necessidade de olhar para as histórias singulares, respeitando as particularidades e a universalidade, entendendo que, como seres de interação, os professores estão inseridos em contextos concretos, constituindo-se de modo permanente.

Palavras-chave: Identidade. Formação de professores. Educação básica.

\section{ABSTRACT}

\section{IDENTITY AND TEACHING TRAINING: METAMORPHOSIS OF A STRUGGLER}

Thinking about the constitution of the teacher identity requires understanding this process as historical, social and cultural, at the same time that is unique, trailed by choices, actions, intentions, feelings and experiences. This paper has as an objective to understand the process of identity formation of a Basic Education teacher in relation to continuing training. The research, of a qualitative nature, sought to know the identity movements of the teacher, with support in the narratives of life stories. The narrative showed that, mediated by the objectivity

\footnotetext{
Doutora em Educação pela Universidade Estadual do Ceará (UECE). Professora Assistente e Professora do Programa de PósGraduação em Educação da Universidade Estadual do Ceará (UECE). E-mail: giovana.falcao@uece.br

** Doutora em Educação pela Universidade Federal do Ceará (UFC). Professora associada da Universidade Estadual do Ceará (UECE), vinculada ao Curso de Pedagogia e ao Programa de Pós-Graduação em Educação. Líder do grupo de pesquisa Educação, Cultura Escolar e Sociedade (EDUCAS/UECE).E-mail: isabelinhasabino@yahoo.com.br

1 A pesquisa foi aprovada em seus aspectos éticos e metodológicos, de acordo com as Diretrizes estabelecidas pela Resolução do Conselho Nacional de Saúde (CNS) no 466/2012) e pelo Comitê de Ética em Pesquisa da Universidade Estadual do Ceará (UECE), através de Parecer no 1.382.058.
} 
of the material world and the relationships established by itself, the teacher has been subjectivated and constituted herself a teacher experiencing this route. Mainly the "struggler" character. The study points the needing to look at singular stories, respecting particularities and universality, understanding that, as beings of interaction, teachers are inserted in concrete contexts, constituting themselves in a permanent way.

Keywords: Identity. Teacher training. Basic education.

\section{RESUMEN}

\section{IDENTIDAD Y FORMACIÓN DOCENTE: METAMORFOSIS DE UNA GUERRERA}

Pensar acerca de la constitución de la identidad docente exige entender este proceso como histórico, social y cultural, al mismo tiempo que singular y trillado por elecciones, acciones, intenciones, sentimientos y vivencias. Este trabajo tiene como objetivo comprender el proceso de constitución de la identidad de una profesora de Educación Primaria en relación a la formación continua. La investigación, de naturaleza cualitativa, busca conocer los movimientos de identidad de la profesora, apoyándose en las narrativas de vida. La narrativa evidenció que mediada por la objetividad del mundo material y por las relaciones que estableció, la profesora se subjetivó y se transformó en docente, vivenciando en este camino principalmente el personaje de "guerrera". El estudio sugiere la necesidad de observar las historias singulares, respetando sus particularidades y la universalidad, entendiendo que como seres de interacción, los profesores están inmersos en contextos concretos que se constituyen de modo permanente. Palabras clave: Identidad. Formación de profesores. Educación primaria.

\section{Introdução}

Entender o processo de constituição identitária do professor exige pensá-lo como movimento relacionado à história de vida, mas também com o contexto histórico, o mundo social e cultural e o conhecimento, aspectos que se encontram em permanente mudança.

0 próprio estudo da temática já traz em si elementos a serem refletidos, posto que a identidade transita por diversas áreas do conhecimento, como a educação, a sociologia, a antropologia, a psicologia, dentre outras. Sendo assim, cada área lança um olhar específico ao tema, dependendo da perspectiva que se quer abordar. Além disso, a identidade é compreendida de modo diverso, conforme as visões de homem e de mundo adotadas pelos pesquisadores.
Ao falar em identidade docente é preciso pensá-la como processo histórico, uma vez que a forma de compreender a profissão foi construída ao longo dos anos, influenciada por aspectos econômicos, políticos e sociais que não podem ser desconsiderados. Ao mesmo tempo, requer o entendimento desse processo como um caminho singular, trilhado por várias escolhas, ações, intenções, sentimentos e vivências. É também coletivo, pois somos seres que nos produzimos nas interações com os outros. Por conseguinte, pensar a identidade docente significa refletir sobre processos coletivos, acontecendo com base em trocas.

Como profissional, o docente vem escrevendo uma história alicerçada em muitos elementos específicos, como a pouca valorização 
profissional, a luta por direitos, o objeto do trabalho etc. Sua ação profissional também contempla características singulares, que podem ser percebidas em sua prática docente, nas relações estabelecidas e na formação profissional. Tudo isso confere a esse profissional elementos de uma identidade própria, processo por demais complexo, plural, que não se pode pensar como algo acabado, estando em permanente devir. Nesta perspectiva, Nóvoa (2000, p. 16) afirma:

A identidade não é um dado adquirido, não é uma propriedade, não é um produto. A identidade é um lugar de lutas e conflitos, é um espaço de construção de maneiras de ser e estar na profissão. Por isso, é mais adequado falar em processo identitário, realçando a mescla dinâmica que caracteriza a maneira de cada um se sente e se diz professor.

A significação social que a profissão assume bem como o sentido que o próprio docente atribui à sua atividade são elementos importantes na compreensão do processo identitário. Destarte, não são raras as falas dos professores denunciando um mal-estar por não se sentirem reconhecidos, valorizados e por se verem negados, muitas vezes, como sujeitos, levando-os a não se reconhecerem naquilo que fazem.

Outro elemento a ser refletido nesse processo de constituição da identidade refere-se ao fazer docente. Diversos estudos apontam a prática docente como um dos pontos mais significativos para a percepção de ser professor. A experiência, no entanto, precisa estar embasada em uma formação profissional, que deve ser contínua e favoreça a autonomia, o pensar. Neste sentido, Farias (2006) aponta que a formação e o trabalho são contextos de socialização que possibilitam ao professor se reconhecer como profissional, construindo-se a partir de suas relações com os saberes e com o exercício da docência.

Consoante a concepção psicossocial de identidade defendida por Ciampa (2000), esta é entendida com origem no sintagma identidade-metamorfose-emancipação e, como tal, é dinâmica, está em permanente constituição, acontecendo ao longo da história, sujeita às transformações sócio-históricas. Para esse autor, o processo tem início desde o nascimento e continua até a morte, podendo, inclusive, ultrapassar os limites biológicos. Ciampa (2000, p. 72) afirma que "[...] é do contexto histórico e social em que o homem vive que decorrem suas determinações e, consequentemente, emergem as possibilidades ou impossibilidades, os modos e as alternativas de identidade".

Ciampa (2000) expressa a noção de que, quando compreendemos a identidade, também entendemos a relação indivíduo-sociedade, reafirmando que este processo subjetivo expressa uma realidade concreta. Para esse autor, o processo identitário faz-se na articulação entre igualdade e diferença, uma vez que vamos nos reconhecendo com base no outro, denotando a importância das relações sociais na individuação. Assim, indagamos sobre as condições em que os docentes alicerçam sua formação profissional e prática docente e como esses elementos intervêm no modo de se reconhecerem docentes. Também é inevitável não pensar sobre a natureza das relações estabelecidas com e entre os profissionais da Educação, assim como acerca da necessidade de fortalecer relações interpessoais baseadas no respeito e na colaboração.

Embora reconheçamos o fato de que muitas inovações aportaram na escola nas últimas décadas (FARIAS, 2002, 2006), a prática profissional docente recebe críticas constantes, por expressar poucas alterações, repetindo aquilo que vem sendo feito há muito tempo. Entender a identidade na perspectiva de metamorfose permite compreender melhor o que está por trás da aparente não mudança e, desse modo, vislumbrar ações formativas que favoreçam processos reflexivos e críticos sobre o fazer docente, atentando para a subjetividade do professor, para os contextos em que estão inseridos e para quem se ensina, processos que certamente favorecerão a metamorfose da identidade docente. 
Considerando a complexidade do ser e fazer-se docente, estudos sobre a identidade se revestem em empreendimento acadêmico relevante, porquanto expressam e explicam o caráter social, histórico, dinâmico e transformador do homem, como aponta Carvalho (2004). Tais estudos nos permitem conhecer de modo mais amplo as condições às quais estão sujeitos os professores, quem são estes sujeitos, quais os sentidos que eles atribuem à carreira docente e como estes elementos se articulam com sua formação profissional e história de vida.

0 presente trabalho tem por objetivo compreender o processo de constituição identitária de uma professora da Educação Básica na relação com a formação continuada. A pesquisa, de natureza qualitativa, buscou conhecer os movimentos identitários da professora, com apoio nas narrativas de história de vida, por meio de entrevistas de história de vida.

Apresentamos, a seguir, o percurso metodológico trilhado na consecução do objetivo.

\section{Percurso metodológico}

A escolha por uma trajetória metodológica revela muito sobre o pesquisador, expressa 0 modo que este compreende ciência, pesquisa e a forma que se relaciona com seu objeto de estudo. Este não é um momento fácil, exigindo do pesquisador cuidado, rigor e coerência. Durante todo o percurso ele precisa estar atento aos objetivos a serem perseguidos, mas, ao mesmo tempo, deve fazer sentido para quem está pesquisando.

Encontramos na abordagem qualitativa sentido para a consecução dos objetivos propostos neste estudo, pois a temática aborda essencialmente elementos de uma subjetividade que precisam ser pensados em maior profundidade a partir de contextos objetivos. Conforme ensina Chizzotti (2003, p. 79): "A abordagem qualitativa parte do fundamento de que há uma relação dinâmica entre o mundo real e o sujeito, uma interdependência viva entre o sujeito e o objeto, um vínculo indissociável entre o mundo objetivo e a subjetividade do sujeito."
É a partir da narrativa de história de vida que pretendemos entender o processo de constituição identitária. Para tanto, ouvimos a professora buscando apreender elementos de sua história, iniciada num tempo mais longínquo de sua vida escolar. Entendemos que a identidade docente se constitui ao longo de uma história, das diversas experiências formativas que vão definindo as escolhas e o jeito de atuação. Sendo assim, ouvir as histórias dos professores permite entendê-los melhor e conhecê-los de modo mais integral. Ao mesmo tempo, ao adentrarmos em histórias singulares, estaremos conhecendo elementos de uma realidade mais abrangente, comum a outros sujeitos.

A entrevista buscou investigar elementos da história de vida dessa professora, dando ênfase à história formativa, a fim de entender o significado desta no processo de constituição identitária. A narrativa foi organizada mediante categorias que permitiram analisar de modo qualitativo as falas da docente. Objetivando manter o anonimato, solicitamos à professora que escolhesse um nome para identifica-la no trabalho, que pediu para ser identificada por Rosinha, nome que diz muito de sua história de vida.

De acordo com Ciampa (2000) e Lima (2010), a Narrativa de História de Vida é expressa como um procedimento apropriado para obter as informações necessárias para a compreensão de como ocorrem as elaborações identitárias. Lima (2010) explica que a escolha desse tipo de instrumento de pesquisa se justifica em razão do potencial que as narrativas de história de vida podem oferecer para a compreensão de como a identidade de uma pessoa foi se metamorfoseando ao longo dos anos com suporte nas influências histórico-sociais.

Em seu trabalho, A Estória do Severino e a História da Severina, Ciampa (2000) usou a narrativa de história de vida como procedimento de escuta da história de sua personagem, argumentando que o meio mais apropriado para analisa-la seria o uso de personagens. Lima (2014, p. 4, grifo do autor) aponta que 
nas narrativas de história de vida, o entrevistador não é mero expectador perante a história narrada, mas “[...] ocupa papel de 'testemunha' do sofrimento, da mortificação ou das possibilidades de subversão e emancipação dos indivíduos". De acordo com Benjamin (1985 apud LIMA, 2010), a utilização da narrativa de história de vida possibilita o surgimento da personagem narrador que, de acordo com esse autor, está em vias de extinção, em virtude de estar esquecido e sufocado, uma vez que traz as contradições do sistema e aponta o mal-estar cotidiano. Como já explicitado, ao narrar a sua história, o sujeito traz a história de outros.

Para Queiroz (1988), a história de vida se define como o relato de um narrador que revela sua existência através do tempo e tenta reconstituir os acontecimentos que vivenciou e a experiência que foi adquirindo. A autora ainda informa que a narrativa dos acontecimentos que o sujeito considera significativos permite delinear as relações sociais que este estabelece com seu grupo, com a sociedade de modo geral e com a profissão.

Gaulejac (2005) aponta que o objetivo da história de vida é ter acesso a uma realidade que ultrapassa quem narra. Desse modo, a história de cada personagem permite entender muito mais do que uma história singular, pois ela nos fornece elementos para entendermos a história de uma coletividade, o universo do qual faz parte, considerando que os contextos exprimem elementos em comum. 0 narrador aborda sua trajetória individual, mas também as trajetórias coletivas, numa relação dialética. Assim, quando um professor relata sua história, ele certamente traz elementos que dizem respeito a outros professores, uma vez que é na articulação entre subjetividade e objetividade que os sujeitos se constituem. Para Ferraroti (1988, p. 26), “[...] nosso sistema social encontra-se integralmente em cada um dos nossos actos, em cada um dos nossos sonhos, delírios, obras comportamentos. E a história deste sistema está contida por inteiro na história de nossa vida individual".
De acordo com Lima (2014), na Psicologia, o uso das narrativas, principalmente no campo da pesquisa em Psicologia Social, também é muito recente. 0 autor relata que a técnica aparece no final dos anos 1940, nos estudos de Oracy Nogueira e Roger Bastide, permanecendo ignorada na Sociologia e na Psicologia por algumas décadas. De acordo com esse autor, o desinteresse se justifica em razão do encantamento com os métodos experimentais e consequente desvalorização de métodos mais subjetivos. No final dos anos 1970, o trabalho de Ecléa Bosi, sobre a memória social, resgata a história de vida como técnica específica habilitada a captar elementos da vida dos sujeitos. Esta passou a ser utilizada tanto na Sociologia como na Psicologia, com base em orientações diferentes na coleta de dados, de acordo com o tipo de pesquisa dos dois campos. A Sociologia buscava nos entrevistados as marcas de seu grupo étnico, camada social e pertença, enquanto a Psicologia demandava as particularidades que singularizavam as pessoas.

Lima (2014) ainda explicita que nos anos 1980, Antonio da Costa Ciampa possibilitou a superação dessa dicotomia social/individual, mostrando que o uso da história de vida vai além de uma técnica de coleta de dados, e exprimiu contribuições metodológicas originais e significativas em seu estudo sobre a metamorfose da identidade intitulado A Estória do Severino e a História de Severina (CIAMPA, 2000).

As variadas tipificações ou classificações no uso das histórias de vida inscrevem-se como uma possibilidade de, com suporte na voz dos agentes sociais, recuperar a singularidade das histórias narradas por sujeitos históricos, socioculturalmente situados, garantindo o seu papel de construtores da história individual/ coletiva intermediada por suas vozes.

A história trazida como relato não é uma representação exata do passado, mas uma maneira de entender o que aconteceu, com arrimo em elementos do presente, levando a novas compreensões. Ao narrar sua história de vida, o professor irá entender como foi se 
constituindo e se percebendo docente, como se vê no presente e projetará expectativas de vir a ser, colocando a forma de se perceber professor em movimento. Bosi (1995) destaca o fato de que o sujeito, ao se lembrar dos acontecimentos que vivenciou, não está apenas revivendo, mas reconstruindo, repensando, com imagens e ideias do presente, as experiências do passado, próximo ou remoto.

A relação entre o pesquisador e o sujeito que narra merece atenção nas narrativas de história de vida. Contar sua história significa ficar exposto, desnudar-se, revelar quem se é. Sem dúvida, não é fácil relatar aspectos de uma história que, muitas vezes, ficaram "esquecidos", "protegidos" num lugar ao qual não se tem acesso, pois rememorá-los pode trazer sofrimento e lembranças nem sempre felizes. É preciso, portanto, estabelecer um vínculo de confiança, oferecendo segurança para que o entrevistado possa se expressar livremente, sem temor. Ouvir a história do outro é ato de grande responsabilidade, exige uma escuta atenta, cuidadosa e, acima de tudo, requer uma atitude ética do pesquisador. Cada relato é expresso com elementos próprios e cada sujeito entrevistado deve ser visto como único, exigindo que o entrevistador perceba a singularidade de cada interação. Consoante Bosi (2003, p. 60), “[...] da qualidade do vínculo vai depender a qualidade da entrevista. Se não fosse assim, a entrevista teria algo semelhante ao fenômeno de mais valia, uma apropriação indébita do tempo e do fôlego do outro".

Apresentamos, a seguir, a narrativa da professora Rosinha, que traz elementos referentes à constituição de seu processo identitário.

\section{Processos constitutivos de uma professora: entre a objetividade e a subjetividade}

A professora participante tem 42 anos, é natural de Itapipoca, cidade localizada no sertão do Ceará, onde morou com a família até os 11 anos de idade, quando, então, foi para Fortaleza estudar na casa de sua madrinha. A numerosa família de 12 irmãos provia seu sustento com a agricultura familiar, enfrentando difíceis condições financeiras. Rosinha casou logo que terminou o Ensino Médio, mas atualmente é separada e tem duas filhas. Graduou-se em Pedagogia, cursando em regime especial pela Universidade Vale do Acaraú (UVA). Cursou, ainda, graduação em História e fez especialização em Ensino Médio pela mesma Universidade. É professora efetiva de seu município há 20 anos. Atualmente, leciona no $1^{\circ}$ e no $5^{\circ}$ ano do Ensino Fundamental, ensinando Geografia. Há um ano leciona no Ensino Superior no curso de Pedagogia pela UVA (regime especial), sendo responsável pela disciplina de Didática. Participou como professora supervisora do Programa Institucional de Bolsas de Iniciação a Docência (PIBID) de 2011 a 2013.

Ao ser indagada sobre "como se tornou quem é", a professora narrou elementos de sua história de vida, trazendo situações e acontecimentos de um tempo mais remoto, revelando em sua fala os aspectos do contexto histórico, social e econômico, bem como das relações familiares que foram significativos na constituição de quem é. A narrativa evidencia o caráter dinâmico da constituição do ser, o que pode ser entendido quando Vygotsky (2009) assinala que o desenvolvimento psicológico do homem vai se constituindo desde as interações que este vai estabelecendo com o mundo, com os outros, sendo mediado por elementos da história e da cultura em que está inserido, ou seja, o desenvolvimento da subjetividade ocorre pelo intercâmbio contínuo do interno com o externo, relação essa que o autor descreve quando se refere à gênese das funções psicológicas superiores.

As falas da professora expressam, de modo claro, como ela foi se constituindo em sua difícil realidade objetiva:

[...] eu não tinha nada, minha família era humilde, muito humilde, minha mãe não tinha condições de nos colocar para estudar. Não 
tenho muita coisa, mas o pouco que eu tenho foi com muita dificuldade, tinha que se deslocar do meu interior, aqui de Itapipoca, pra Fortaleza, morar com parentes pra poder estudar. Por isso que eu digo que eu sou guerreira! (ROSINHA, grifo nosso).

Mediada pela relação dialética entre as dimensões objetiva e subjetiva, a professora foi se constituindo. As condições objetivas que vivenciou foram definindo o seu modo de ser e agir no mundo, de se relacionar e de se reconhecer. Para Vygotsky (2009), quando nos apropriamos da cultura humana, vamos produzindo significados e sentidos acerca dela. A maneira como cada um vai significando o mundo provoca modos de pensar, sentir e agir que se diferenciam.

Rosinha revela as limitações vivenciadas no contexto social, situação ainda tão presente na realidade de muitos brasileiros, principalmente nas regiões Norte e Nordeste, onde o acesso ao estudo ainda se exprime como uma dificuldade e o trabalho infantil continua uma realidade. Em sua fala deixa claro que resiste às adversidades que a vida lhe oferece, enfrentando os desafios, mesmo quando as condições não favorecem. As difíceis condições não foram suficientes para imobilizá-la, pois Rosinha buscou condições para estudar, o que desvela sua capacidade de se mover, de não se acomodar, revelando sua coragem de enfrentar desafios.

Quando enfrenta a realidade objetiva, Rosinha vai se subjetivando. De acordo com Aguiar e Bock (2011), ao produzir os meios para satisfação de suas necessidades, o homem se apropria da realidade objetiva, transformando-a numa nova realidade, de perfil subjetivo. Ao retornar para a realidade, sua subjetividade objetiva-se novamente, numa permanente produção da realidade e de si mesmo. Criando e recriando o novo, o homem produz nova realidade objetiva, ao mesmo tempo em que produz a sua realidade subjetiva.

Quando Rosinha diz: "eu não tinha nada”, e mais à frente expressa: "o pouco que eu tenho foi com muita dificuldade", parece referir que conseguiu superar algumas das dificuldades de seu contexto. Este movimento acontece com a busca pela escola: "minha mãe não tinha condições de nos colocar para estudar", "morar com parentes pra poder estudar", trazendo significações que revelam o grande valor que atribui ao estudo, o que talvez explique a sua necessidade incessante por aprender, que se revelou em muitos momentos de sua narrativa. Afanasiev (1978) nos ajuda a entender essa necessidade da professora, quando postula a ideia de que as necessidades humanas não têm existência em si, mas são elaborações sociais e históricas que mobilizam o ser humano a agir. Por outro lado, pensar que a escola sozinha dará conta de transformar toda uma realidade social que se mostra precariamente é, no mínimo, ingênuo.

Lutando contra a vida, que lhe impunha uma situação socioeconômica marcada por adversidades, foi se constituindo "guerreira" e encarnando esta personagem: "por isso que eu digo, que eu sou guerreira!". Para Ciampa (2000), a identidade se expressa empiricamente por meio de personagens, sendo a articulação dessas personagens o que vai compor a identidade da pessoa. 0 autor explica que este é um modo subjetivado dos papéis sociais, constituintes do acervo social, e por via dos papéis sociais é dada a possibilidade de o indivíduo agir no mundo e objetivar, ainda que parcialmente, sua identidade. Em sendo assim, a personagem "guerreira" foi se constituindo com suporte nos vários acontecimentos de seu contexto, ao mesmo tempo que se reconhece como tal. É como "guerreira" que enfrenta as dificuldades que a vida lhe impõe e que vai se constituindo a professora que "luta por justiça".

No mesmo sentido, Ciampa (2000) compreende que é com base no outro que vamos constituindo nossa identidade. De acordo com o autor, quando tomo o outro como referência, eu me diferencio dele, porque não sou ele e, desse modo, somos reconhecidos e reconhecemo-nos diferentes do outro. 
A fala de Rosinha deixa claro como a tia, a quem chama de mãe adotiva, e em outro momento a nomeia de madrinha, mediou seu processo constitutivo. A "guerreira" que saiu de casa para estudar na casa de parentes encontrou na nova morada apoio, carinho e uma referência a seguir:

Em Fortaleza morei na casa da minha tia, que hoje é minha mãe adotiva. Ela que me formou estruturalmente, ela que me deu carinho, que me deu atenção. Tudo o que eu sei hoje, em termos de cultura, foi ela que proporcionou, certo, só que ao invés de ter casado, ter terminado os estudos lá, voltei pra Itapipoca, e na verdade eu terminei o curso superior aqui. (ROSINHA, grifo nosso).

Sua nova condição favoreceu, além da possibilidade de estudar na escola, outras perspectivas, distintas aprendizagens, novas referências e uma relação de muito afeto com a madrinha, elementos que foram significativos para a constituição de quem Rosinha foi se tornando. Ao escolher Rosinha como o nome para ser identificada na pesquisa, esta professora explica que é assim que a sua madrinha a chama; nome que expressa, de algum modo, a contradição que vivia: o afeto e a luta. Desse modo, reafirma a importância que essa pessoa teve em sua constituição identitária. A menina "guerreira" foi se transformando e assumindo características valorizadas pela madrinha, como a criticidade: [...] "minha madrinha nunca foi fácil, então ela sempre me incentivou a criticar. Eu digo pra ela que nem um filho biológico herdou tanto como eu herdei" (ROSINHA).

Agindo de maneira sempre crítica, assim como a madrinha, que, segundo ela, "nunca foi fácil", assume essa característica em seu modo de ser professora, revelando em seus relatos que sempre critica o que a incomoda, mesmo quando esta atitude não é bem entendida por muitos. 0 novo contexto e a relação com a "nova mãe" mediaram as transformações em Rosinha.

Ciampa (2000, p. 127) ressalta que "no seu conjunto as identidades constituem a sociedade, ao mesmo tempo em que são constituídas, cada uma por ela". A professora foi constituin- do sua identidade, se subjetivando, na relação com o outro, nos contextos em que transitou ao mesmo tempo em que constitui essa sociedade.

Rosinha, que se reconhece como "guerreira" por lutar contra as adversidades da vida, luta bravamente contra as adversidades de um contexto marcado pela pobreza material e a falta de acesso ao estudo. Contando sua história, a professora reconhece sua capacidade de superar as dificuldades: "eu diria que a vida diz que eu não posso e eu digo que posso".

Continuando sua fala, vai revelando o que significa sua busca por se qualificar positivamente. Rosinha entende que é através do estudo que se consegue vencer. Essa compreensão pode ser visualizada em sua narrativa quando retrata, com orgulho, a conquista da família em ter quatro professoras formadas e identifica, também, a mãe como "guerreira", por ter contribuído para que as filhas conseguissem esse feito, considerando as difíceis condições socioeconômicas da família.

Tenho 11 irmãos. Na verdade, eu tenho 3, 4 irmãs professoras, formadas e tudo. A minha mãe foi uma guerreira, né? Apesar dos pesares ela conseguiu 4 filhos formados, dentro das possibilidades que existiam. Fui morar com minha madrinha porque as condições financeiras eram difíceis. Eu mesma que tinha muita vontade de vencer na vida, devido à situação familiar. (ROSINHA, grifo nosso).

Em sua fala, a professora deixa claro que buscava superar as dificuldades vivenciadas pela família: "eu mesma que tinha muita vontade de vencer na vida devido à situação familiar". Parece entender, no entanto, que esta é uma busca individual, que depende somente daquele que quer conseguir, sendo, portanto, uma situação naturalizada. Em nenhum momento questiona as desigualdades do contexto e o porquê de tantas dificuldades, não faz uma reflexão mais crítica sobre a difícil realidade vivenciada por ela e por tantas outras pessoas.

Em outro momento, reitera a noção de que os constantes desafios vivenciados ao longo da vida favoreceram o enfrentamento destemido das situações desafiadoras: 
Não foi fácil, eu tive muita dificuldade. Como eu disse, os desafios foram grandes, mas eu sou perseverante, eu digo guerreira, que sou mesmo, não baixo a cabeça com facilidade. Aí eu fui..., aí eu fui... cada hora que passa eu tenho novos desafios, novos planos. Agora o novo desafio é que eu sou professora, estou iniciando como professora acadêmica, professora do nível superior; é um desafio porque eu preciso estudar. Outro desafio grande hoje, que o PIBID me abriu as portas, foi a questão da tecnologia, que eu não sabia manipular; hoje estou iniciando datashow, essas coisas, whatsapp, o próprio celular, que o PIBID abriu as portas, me despertou para isso, eu agradeço muito ao PIBID por isso que eu estou aqui. (ROSINHA, grifo nosso).

Certamente, por se reconhecer como "guerreira", não se imobiliza diante dos desafios; ao contrário, ela os busca, na tentativa de ir cada vez mais longe. Com efeito, à medida que enfrenta as novas situações, a personagem "guerreira" vai se metamorfoseando (CIAMPA, 2000). Ela agora não luta apenas pela sobrevivência ou para permanecer na escola, luta para melhor se qualificar: "estou iniciando como professora acadêmica, professora do nível superior, é um desafio porque eu preciso estudar." (ROSINHA). Também menciona que hoje está tendo acesso e fazendo uso da tecnologia, algo que até bem pouco tempo não dominava, o que aconteceu por ter aceito o desafio de participar do PIBID. As muitas aprendizagens vão ampliando seu repertório de saberes e favorecendo novas maneiras de atuar em seu cotidiano, e, desse modo, Rosinha vai assumindo outras personagens.

As condições objetivas vivenciadas por ela foram, então, mediando o modo de se apresentar no mundo e foram sendo convertidas em significações pessoais. De acordo com Pino (2000, p. 69), a mediação social se constitui da seguinte forma: "o que é social se converte em pessoal e o que é pessoal se converte em social."

Dialeticamente, o outro vai fazendo uma imagem sobre nós desde como nos expressamos no mundo. De acordo com Ciampa (2000, p. 13), "interiorizamos aquilo que os outros nos atribuem de tal forma que se torna algo nosso. A tendência é nos predicarmos coisas que os outros nos atribuem." Esse autor esclarece que desde que nascemos nos é atribuído um nome, que inicialmente é externo a nós mesmos, ou seja, o recém-nascido não tem consciência de que aquele nome o representa, somente depois isso acontece: "um nome nos identifica e nós com ele nos identificamos." (CIAMPA, 2000, p. 131). Não conseguimos nos reconhecer com outro nome que não o que nos foi atribuído. Nosso nome se funde a nós, confirma e autentica nossa identidade, sendo o símbolo de nós mesmos, como aponta Ciampa (2000). Nosso nome, todavia, não é nossa identidade, mas é uma representação dela. Desse modo, a identidade vai assumindo outras predicações, por meio de papéis que vamos vivenciando ao longo de nossa vida. Esse autor defende que a forma personagem explica melhor este processo na sua generalidade. É na relação com o outro que vamos nos tornando quem somos, sendo este um processo permanente, que nunca se encerra.

A professora também explicita a importância do outro em seu processo de reconhecimento.

Eu acho que, assim, a gente pra se reconhecer, a gente não se reconhece, a gente não sabe falar da gente mesmo, todo ser humano tem essa complicação, né? A gente fala dos outros, vê os outros, elogia os outros, mas a gente mesmo, não. Eu acho que... pelo o que eu pude observar, é isso: as pessoas me acham dedicada, responsável, uma boa mãe. Eu acho que eu sou uma boa cidadã, acho que desempenho bem o papel de cidadã, pelo menos eu batalho para isso. (ROSINHA, grifo nosso).

Embora em outros momentos de sua narrativa tenha se definido várias vezes como "guerreira", Rosinha garante que falar de si é algo difícil, o que a leva a se olhar com base no que o outro expressa sobre ela: “[...] a gente não sabe falar da gente mesmo." E continua apontando uma definição de si desde como imagina que os outros a definem: "[...] me acham dedicada, responsável, uma boa mãe." Sua fala não revela se concorda com tais atributos e também não 
deixa claro quem a vê assim. Nas características que reúne, traz adjetivos que podem defini-la nos vários papéis que desempenha: “[...] dedicada, responsável”, mas ressalta o de mãe, que em outro momento relaciona ao papel de professora. Rosinha vai se reconhecendo com arrimo na significação do outro sobre si. Ao falar, entretanto, parece que vai pensando sobre ela, tomando consciência de quem é, ao mesmo tempo em que vai elaborando uma definição sobre si: "[...] acho que desempenho bem o papel de cidadã." De acordo com Cunha (1997), a narrativa de si tem o propósito de fazer a pessoa se tornar visível para ela mesma. A guerreira vai se tornando então "boa cidadã", que defende aquilo que acredita ser o correto, como expressa em outro momento de sua fala.

Ao ser indagada sobre o modo como era reconhecida por seus alunos, não conseguiu identificar com clareza como é vista por eles.

Eu acredito que eles [alunos] gostem de mim, mas eu não sei, porque aluno é complicado, o ser humano é complicado, às vezes você acha que a pessoa gosta de você e na verdade não gosta, acha você interessante e não é, então o ser humano [...] Hoje, você que tem uma experiência humana, você sabe que não pode confiar em todo mundo e nem no que as pessoas dizem, porque às vezes é da boca para fora. (ROSINHA, grifo nosso).

A professora expressa imaginar que os alunos gostem dela, porém não explica porque acha isso. Ao mesmo tempo em que diz não ter certeza sobre os sentimentos dos alunos em relação a ela: "[...] às vezes você acha que a pessoa gosta de você e na verdade não gosta." Revela em seguida descrença do ser humano, que, segundo ela, não é digno de confiança. Sua posição defensiva é revelada em outros momentos de sua narrativa, mostrando que em razão de muitas situações vivenciadas, hoje é "autodefensiva". A guerreira precisa estar sempre alerta! Mais uma vez, é possível perceber como os elementos da objetividade vão interferindo em sua subjetividade, constituindo quem ela é. Chama atenção o fato de a professora não saber como seus alunos a veem.
Rosinha os situa na categoria "ser humano", e, como tal, podem não ser confiáveis.

0 reconhecimento se configura como o jogo entre o eu e o outro, o nós e o eles, entre a parte e o todo social, como assinalam Gonçalves Neto e Lima (2011). Ao olhar para a história de reconhecimento de Rosinha, constatamos que ela traz aspectos configurados não apenas como história singular, mas também representa a história de muitos outros professores. Ainda para esses autores, analisar a constituição identitária de pessoas ou grupos, e seu reconhecimento, tem importante implicação política, pois, dependendo do modo como eles se reconhecem ou são reconhecidos, "determinadas práticas em relação a eles, ou para eles, ou mesmo contra eles, são levadas a cabo. Assim, direitos são garantidos, deveres são cobrados, penas são aplicadas, preconceitos são combatidos" (GONÇALVES NETO; LIMA, 2011, p. 95).

0 acesso à escola, para a professora Rosinha, como já comentado, também não foi fácil. Em sua narrativa, nos conta que ingressou na escola tardiamente, com 11 anos de idade.

Eu entrei com 11 anos, aí você imagina, eu com 11 anos e os meninos com 7 anos. Em Fortaleza, eu estudava naquela escola, Maria Celeste, acho que até hoje existe, no Benfica. Ficava ali, quase numa favela que tinha. É uma escola municipal, me marcou muito a escola. Eu fiz alfabetização, $1^{\circ}, 2^{\circ}$ e $3^{\circ}$ ano. Só que eu era fora de faixa, certo? E eu me sentia estranha porque eu era a mais velha da sala. Já era uma mocinha quando eu entrei no 1o ano, então [...] mas mesmo assim eu acompanhei bem direitinho, os alunos me aceitavam, os professores me aceitavam, mas eu não aceitava era as regras. Assim, se a professora fosse injusta, eu criticava, eu reclamava, aí ela dizia assim: 'Mas por que você critica?' Porque a grande maioria dos alunos, na época, ou até hoje mesmo, eles falam mas eles não têm uma consciência do que estão falando. Eu sempre tive, devido à minha madrinha, devido a ela sempre ter me criado... como é que se diz... Ela me criava, assim, com personalidade. Devido à minha personalidade, criticidade, eu sempre fui crítica, até mesmo quando criança, então eu não aceitava tudo. Se a professora... Por exemplo, a professora da alfabetização, ela fazia 
diferença de criança e eu não aceitava isso, para mim era para ser igual e eu geralmente criticava ela, falava, comentava, e ela não gostava. (ROSINHA, grifo nosso).

Em seu relato, Rosinha expressa que se sentia estranha em razão da diferença de idade em relação aos colegas: "E eu me sentia estranha porque eu era a mais velha." E segue contando que, mesmo assim, acompanhava o conteúdo e se sentia aceita por colegas e professores, dando a entender que, apesar das circunstâncias, se orgulhava em ter conseguido superar as dificuldades. Também revela que, desde então, se apresentava crítica aos acontecimentos da sala de aula, o que nem sempre agradava a professora. Justifica que a madrinha a incentiva a ser crítica, característica que, em outros momentos de sua narrativa, ressalta possuir. Ao assumir-se crítica, assim como a madrinha, revela a presença e a força do outro e do social na constituição de sua identidade. Assim, quando diz que não acata as injustiças, parece falar que não aceita as condições injustas de vida impostas a ela. Lutando pelo que acredita ser o correto, Rosinha amplia sua história e revela o quanto resistiu em aceitar o papel que as limitações do contexto social lhe reservavam.

Transformando sua realidade em objeto de estudo, na pós-graduação, ressalta que conseguiu prosseguir estudando porque teve ajuda, provavelmente da madrinha, que era seu suporte, mesma ajuda que cobra dos pais dos alunos, ao mesmo tempo em que tenta oferecer a estes o apoio "maternal" que recebeu: "Eu falo muito dos meus alunos, porque quando eu leciono, eles são como meus filhos." Agindo como professora-mãe, ela significa a ideia de que, como professora, deve oferecer apoio, incentivo. Embora tenha enfrentado uma realidade desafiante, Rosinha significa sua luta de maneira positiva, o que a leva a buscar estudar sua realidade e a tentar oferecer aos alunos o apoio que julga necessário. De acordo com Soares e Aguiar (2012), a qualidade das ações é mediada historicamente pelo modo como cada um significa o que faz, bem como pela disponibilidade dos recursos objetivos para agir. Sem dúvida, essas experiências e a relação estabelecida com a madrinha mediaram seu jeito de ser professora.

Seguindo em sua narrativa, a participante conta que não queria ser professora, mas por sugestão da madrinha e por falta de oportunidade fez o curso pedagógico e depois graduação em Pedagogia e História. Ela nos diz:

Na verdade, eu não queria ser professora, foi um acaso. Quando eu estava em Fortaleza, que eu fiz o técnico em Pedagogia, que era o técnico de magistério, foi por acaso. Eu ia fazer o científico, porque se eu tivesse ido fazer o científico eu não tinha ingressado no magistério, tinha feito outra área, Direito ou alguma coisa do tipo. Optei pelo técnico em Pedagogia devido a minha madrinha, que era minha mãe, porque ela incentivou, por incentivo dela, não por mim. (ROSINHA, grifo nosso).

Mais uma vez faz referência à figura da madrinha mediando seu processo constitutivo. A "guerreira que luta por justiça" assinala que não queria ser professora e cita que talvez tivesse feito o curso de Direito, não fosse o "incentivo" da madrinha: "optei pelo técnico em Pedagogia devido a minha madrinha." A confiança naquela que identifica como mãe e que tão bem a acolheu foi decisiva para que trilhasse esse caminho.

Embora não tendo sido sua escolha, Rosinha conta que se identificou com o curso de Pedagogia, principalmente por que aí "aprendeu a trabalhar com gente". Ao narrar sobre a formação continuada, a professora dá destaque para a experiência vivenciada no PIBID.

Com o PIBID eu melhorei bastante. Você pode dizer assim: "como é que pode?" Mas é verdade mesmo, eu melhorei, comecei a ler, comecei a acreditar mais na educação, foi um incentivo muito grande à leitura, gostar mais do que eu fazia, me identificar. Sempre gostei muito de criança, e comecei a trabalhar com criança novamente [...] é como se eu fosse atrás dos meus objetivos e, principalmente, do que eu quero, dos meus sonhos. (ROSINHA, grifo nosso). 
Para a professora, ler, refletir sobre o trabalho e todas as atividades vivenciadas no Programa foram importantes para que desse novo significado à profissão docente, pois, quando foi convidada a escolher uma imagem que identificasse como se sentia antes do Programa, escolheu uma figura em que um machado aparecia sobre a cabeça de uma pessoa, representando o peso, o sofrimento que ser professor estava lhe causando. Significando a docência de modo positivo a partir do Programa, vai se sentindo fortalecida e reconhece que é capaz. A "guerreira" se sente preparada para lutar por seus objetivos.

Ao contar sobre o ingresso na docência, Rosinha expressa que iniciou em um estágio remunerado, experiência que parece ter sido pouco significativa para ela, pois ao contar sua história, não havia mencionado esse fato, apenas citou rapidamente que ingressou na escola como estagiária e que assumiu a regência de sala de aula, pois a professora titular precisou se ausentar. Desse modo, entendemos que a experiência não foi muito positiva para ela, porquanto revelou não querer ser professora após a conclusão da habilitação em magistério. Um novo fato mudou os planos de Rosinha. Ao concluir o curso, ela se casou e voltou para a cidade de seus pais no interior do Ceará, e nos conta: "Como eu tinha acabado de me casar e não tinha outra profissão, então eu fui para o magistério." Embora não quisesse ser professora, Rosinha fez a formação e essa se exprimia como a única possibilidade para ela, que precisava trabalhar.

As condições econômicas e a falta de oportunidades em seu município levaram Rosinha a ingressar na docência. Ela diz: “[...] mas não fui gostando". A identificação com a profissão aconteceu à medida que trabalhou com as crianças e entendeu a sua responsabilidade no desenvolvimento destas: "[...] é como se fosse o único norte que eles têm, então, se a gente não acreditar, eles não têm nada." Rosinha passou então a significar a docência como uma responsabilidade social; significação que produziu sentidos no modo de se reconhecer docente. A professora nos conta ainda que a experiência vivenciada no PIBID também possibilitou novos elementos na forma de entender a docência e, assim, nos sentidos que atribui à profissão. Em outro momento, nos contou que foi no Programa que entendeu o que é "ser educador", referindo-se ao professor como agente de mudanças. Por fim, relata que a identificação com colegas que veem na Educação a possibilidade de transformar a realidade é muito importante para fortalecer seu reconhecimento como docente.

Rosinha aponta, em sua narrativa, diversas problemáticas enfrentadas em seu município, no exercício da profissão. Ela nos diz das precárias condições de trabalho; em sua narrativa nos contou que após sua participação no PIBID, se submeteu a uma seleção para assumir uma função na Coordenadoria Regional de Desenvolvimento da Educação (CREDE) ${ }^{2}$ como formadora, mas, ao iniciar, não se identificou com o modo como trabalhavam, pois, de acordo com Rosinha, criticavam o professor sem se preocupar com as dificuldades vivenciadas por este em sala de aula. Ela nos fala:

Eu sei da dificuldade de que é uma sala, sala de aula não é fácil! É muito fácil você tá fora de sala e dizer o que é, é muito fácil escrever, fazer pesquisa; fazer pesquisa você pega 2,3 alunos. Sala de aula você pega 35, com adversidades, diversas adversidades possíveis, desde a iluminação, a quentura, muitas vezes você sai de sala de aula prá respirar, porque você tá molhada de suor, e você vê o aluno se derretendo e você não pode fazer nada, porque o sistema não quer, o sistema não está nem aí pro aluno. Aí eu vi que a única possibilidade deu mudar alguma coisa era na sala de aula,

2 A CREDE surge com a extinção das Delegacias Regionais de Educação (DERE) pelo Decreto no 24.274, de 22/12/96. Em 26 de dezembro de 2007, o Decreto no 29.139, Art.4ㄹ, altera a estrutura organizacional básica e setorial da Secretaria da Educação (SEDUC). 0 governador do Estado do Ceará institui como órgão de execução local e regional vinte (20) Coordenadorias Regionais de Desenvolvimento da Educação (CREDE) e as Superintendências das Escolas Estaduais de Fortaleza. Em Itapipoca funciona a 2 ${ }^{\underline{a}}$ CREDE, regional que acompanha a instituição em que Rosinha se encontra. 
não era sentada numa CREDE. Ali eu ia só [...] terminar meus anos. (ROSINHA, grifo nosso).

Seu relato é forte e expressa a falta de condições básicas para aluno e o professor permanecerem em sala. Aprender e ensinar nessas condições, sem dúvida, é algo difícil de acontecer. Rosinha critica o relativo descaso com a Educação por parte dos governantes de seu Município e, como professora, se identifica com as dificuldades vividas por seus pares, entendendo que é ao lado deles que poderá melhor contribuir. A guerreira continua lutando e se metamorfoseando, agora não mais para sobreviver, para estudar, mas por melhores condições de ensino e aprendizagem. Como professora, significa que precisa exercer papel ativo em favor de uma educação de melhor qualidade.

O sentimento de indignação é muito intenso na fala dessa professora. Quando nos encontramos para a entrevista, ela nos contou que estava de licença-saúde há um mês. Não mencionou, porém, o motivo. No momento em que narrava sobre as difíceis condições da Educação no município, nos contou o seguinte fato:

Eu fui para a escolha do livro didático, agora esse ano. Foi o que mais me decepcionou, tanto é que eu estou de licença mais por decepção mesmo, da educação [...] de muitas coisas, sabe? E essa do livro me derrubou! Por quê? A escolha do livro já era programada com uma certa editora, daí não foi democrático, os professores não têm união, não há aquela união. Muitas vezes eles não conhecem o assunto e impõem a sua vontade e acabam escolhendo um livro que não é adequado para o aluno e, além do mais, dentro da reunião eles mesmo anunciaram que no próximo ano o aluno iniciará o ano sem o livro didático, sem o livro do PAIC. Então, quer dizer, provavelmente, no próximo ano, o $1^{\mathrm{O}}$ ano, o aluno vai ficar até maio, até junho sem livro. Então, o que o professor vai ter? Quer dizer [...] nada! Eles mesmo anunciaram. Então, quer dizer, qual o estímulo que você como professor tem? (ROSINHA, grifo nosso).

Sua fala externa decepção, sofrimento e compromisso com os alunos. Ao mesmo tempo, faz séria denúncia sobre um processo que se diz democrático e que na verdade não foi. Para esta professora, a escolha do livro levou em conta outros interesses que não a preocupação com a qualidade do ensino. Rosinha responsabiliza os professores por fazerem parte deste processo tendencioso: “[...] os professores, eles não têm união, não há aquela união." e questiona o direito negado ao aluno de ter o material de estudo. Em outro momento de sua fala, informa que o professor não tem o material básico para trabalhar: "[...] o professor fica procurando recursos seus, se ele quiser alguma coisa você tem que buscar recursos do seu bolso, ou então o que ele tem em casa, ou então catando, mendigando recursos na própria escola." A consciência das precárias condições de trabalho evidenciadas pela professora a deixa atônita, sem conseguir vislumbrar qual o caminho que deverá seguir e, ao mesmo tempo, a faz se sentir impotente diante das constatações ao ponto de adoecer: "E essa do livro me derrubou"! "[...] então o que o professor vai ter?"

Rosinha revela um olhar crítico diante de sua realidade que, na acepção freireana, poderia ser entendido como o desenvolvimento de uma conscientização. Para Paulo Freire (1980, p. 30), a conscientização "[...] implica que os homens assumam o papel de sujeitos que fazem e refazem o mundo. Exige que os homens criem sua existência com um material que a vida lhes oferece [...]"

Em sua escola, Rosinha é reconhecida entre os colegas por exercer certa liderança, segundo ela identifica, sendo porta-voz do grupo pelo fato de reivindicar aquilo que julga ser o correto.

Atualmente, por exemplo, eu tenho uma colega, não vou citar o nome porque é antiético, eu observo que ela gosta de estar perto de mim porque eu exerço um certo domínio na escola, que eu sou dominante! Eu percebo que quando eu estou numa reunião, quando eu tô num grupo, eu tenho um grupinho, que não é que domine, eu falo o que é certo, nós falamos o que é certo, reivindicamos o que é certo, então [...] enquanto tem outro grupo que [...] é 'Maria vai com as outras', mas em compensação eles 
têm que ficar com a direção, do lado da direção, e a gente não fica do lado de ninguém, fica do lado certo, e quem fica do lado certo é contra a hierarquia, por isso que eu tenho um certo cuidado. (ROSINHA, grifo nosso).

Sentindo-se sujeito nessa história, ela luta por aquilo em que acredita. Rosinha se vê através do outro, pois, assim como essas crianças, também enfrentou muitas dificuldades para continuar estudando. A guerreira vem se metamorfoseando e, sendo assim, se faz o outro que também sou eu (CIAMPA, 2000). Neste sentido, podemos entender que sua identidade caminha para uma alterização, para a mesmidade.

\section{Considerações finais}

Conhecer elementos do processo identitário da professora participante possibilitou vislumbrar a noção de que o reconhecimento de si vai se constituindo desde o reconhecimento do outro. Compreender a identidade como fenômeno psicossocial revela que este é um processo social e histórico. Assim, a professora foi constituindo sua identidade mediada pelas vivências e interações estabelecidas nos diversos contextos em que transitou. Ao mesmo tempo em que se iguala ao outro, Rosinha se diferencia, porque não é este outro. Sendo assim, a participante foi encarnando personagens, sendo que algumas vêm sendo repostas ao longo de sua história; outras, porém, sinalizam para uma movimentação.

Ao embarcar na história de vida de Rosinha, foi possível adentrar em contextos históricos, sociais e culturais marcados por problemas econômicos e financeiros, dificuldades de acesso e permanência nos estudos, processos formativos frágeis, espaços educacionais permeados de problemas, elementos importantes nos processos constitutivos da professora participante. Mediada pela objetividade do mundo material e pelas relações que estabeleceu, Rosinha se subjetivou e se constituiu docente, vivenciando neste percurso, principalmente, a personagem "guerreira".
A professora torna-se guerreira ainda criança para lutar pela vida e pela possibilidade de estudar e, como guerreira, enfrenta várias lutas. As condições objetivas e a relação que estabelece com a madrinha são aspectos importantes em seu processo constitutivo. No PIBID, entende a Educação como possibilidade de transformação social e assume novas personagens. Como professora do Ensino Superior, intenta continuar aprendendo sempre.

Conhecer a história de vida da professora, como ela se constituiu, possibilitou entender as personagens que assumiu, o que permitiu compreender com maior riqueza a professora que hoje é, afinal, quem somos hoje é processo histórico, que se inicia num contexto concreto, em tempo mais remoto. Tais aspectos precisam ser considerados nas formações docentes, entendendo que, quando estas acontecem de modo contingencial, descoladas da realidade do docente, não conseguem atingir as subjetividades, mas uniformizam os sujeitos, como se todos fossem iguais e devessem aprender e oferecer os mesmos resultados. Necessário se faz olhar para as histórias singulares, respeitando as particularidades e a universalidade, entendendo que como seres de interação os professores estão inseridos em contextos concretos, constituindo-se de modo permanente. 0 estudo também chama atenção para a necessidade de se ouvir o professor. Em sua fala, Rosinha expressa surpresa, ao mesmo tempo em que demonstra contentamento por ser ouvida, revelando, assim, que pouco se escuta o professor.

\section{REFERÊNCIAS}

AFANASIEV, V. Fundamentos de Filosofia. Rio de Janeiro: Civilização Brasileira, 1978.

AGUIAR, W. M. J.; BOCK, A. M. B. Apreensão dos sentidos: a busca do método. In: MAGALHÃES, M. C. C.; FIDALGO, S. S. (org.). Questões de método e de linguagem na formação docente. Campinas, SP: Mercado de Letras, 2011. p. 149-161.

BOSI, E. Memória e sociedade - lembranças de velhos. São Paulo: Cia das Letras, 1995. 
BOSI, E. 0 tempo vivo da memória: ensaios de Psicologia Social. São Paulo: Ateliê Editorial, 2003.

CARVALHO, M. V. C. Histórias de ser e fazer-se educador: desvelando a identidade do professor universitário e suas possibilidades emancipatórias. 2004. 284 f. Tese (Doutorado em Educação) Pontifícia Universidade Católica de São Paulo (PUC/ SP), São Paulo, 2004.

CHIZZOTTI, A. Pesquisa em ciências humanas e sociais. 6. ed. São Paulo: Cortez, 2003.

CIAMPA, A. da C. A estória do Severino e a história da Severina. São Paulo: Brasiliense, 2000.

CUNHA, M. I. da. Conta-me agora! As narrativas como alternativas pedagógicas na pesquisa e no ensino. Revista da Faculdade de Educação de São Paulo, v. 23, n. 1-2, 1997.

FARIAS, I. M. S. de. Inovação, mudança e cultura docente. Brasília, DF: Liber Livro, 2006.

FARIAS, I. M.S. de. Inovação e mudança: implicações sobre a cultura dos professores. 2002. $260 \mathrm{f}$. Tese (Doutorado em Educação) - Universidade Federal do Ceará (UFC), Fortaleza, 2002.

FERRAROTI, F. Sobre a autonomia do método biográfico. In: NÓVOA, A.; FINGER, M. (org.). 0 método (auto) biográfico e a formação. Lisboa: MS/DRHS/CFAP, 1988. p. 37-50.

FREIRE, P. Conscientização: teoria e prática da libertação - uma introdução ao pensamento de Paulo Freire. 3. ed. São Paulo: Cortez \& Moraes, 1980.
GAULEJAC, V. de. La societé malade de la gestion: idéologie gestionnaire, pourvoir anagérial e harcèlement social. Paris: Seuil, 2005.

GONÇALVES NETO, J. U.; LIMA, A. F. A história de Maria. Psicología, conocimiento y sociedad, $n$. 3, p. 30-51, 2011.

LIMA, A. F. Metamorfose, anamorfose e reconhecimento perverso: a identidade na perspectiva da Psicologia Social Crítica. São Paulo: FAPESP/ EDUC, 2010.

LIMA, A. F. Metodologias de pesquisa em Psicologia Social Crítica. Porto Alegre: Sulina, 2014.

NÓVOA, A. Os professores e as histórias da sua vida. In: NÓVOA, A. (org.). Vidas de professores. 2. ed. Porto: Porto Editora, 2000. p. 11-30.

PINO, A. O social e o cultural na obra de Vigotski. Educação e Sociedade, v. 21, n. 71, p. 45-78, 2000.

QUEIROZ, M. I. P. Relatos orais: do "indizível" ao "dizível". In: QUEIROZ, M. I. P. Et al (org.). Experimentos com histórias de vida (Itália-Brasil). São Paulo: Vértice, 1988. p. 14-43.

SOARES, J. R.; AGUIAR, W. M. J. de. Movimentos de reflexão e possibilidades de mudança do professor na atividade de sala de aula. In: CASTRO, M. R. (org.). Investigação do trabalho docente: sujeitos e percursos. Rio de Janeiro: Caetés, 2012. p. 83-105.

VYGOSTKY, L. S. A construção do pensamento e da linguagem. São Paulo: Martins Fontes, 2009.

Recebido em: 07/01/2020

Aprovado em: 11/03/2020 